\title{
Do desenvolvimento desigual e combinado ao desenvolvimento geográfico desigual
}

Ivo Marcos Theis - Economista, doutor em Geografia pela Universität Tübingen [Alemanha], coordenador do Núcleo de Pesquisas em Desenvolvimento Regional, professor da Universidade de Blumenau e pesquisador do CNPq. Email: ivo.theis@pq.cnpq.br

\section{Resumo}

O propósito que se tem com este artigo é revisitar a lei do desenvolvimento desigual e combinado, com especial atenção para a sua contribuição à geografia do capitalismo mundializado. Embora a origem dessa conhecida lei esteja em Marx, ela acabaria sendo formulada, nos termos que aqui importam, por Leon Trotsky. O nexo geográfico é óbvio. Todavia, é apenas desde o início dos anos 1980 que a Geografia (sobretudo, por intermédio de David Harvey e Neil Smith) conduz a questão das desigualdades sócio-espaciais para o centro do debate. Tendo em vista o propósito mencionado, dividiu-se o texto em duas seções (além da introdução e das considerações finais): na primeira, caracteriza-se o desenvolvimento desigual na sua aproximação com a lei do desenvolvimento desigual e combinado; a segunda consiste da discussão do caráter especificamente geográfico do desenvolvimento desigual. Nas considerações finais resgatam-se os diálogos travados por alguns intelectuais brasileiros com a lei do desenvolvimento desigual e combinado, assim como suas contribuições (involuntárias) para o enfoque do desenvolvimento geográfico desigual. Por fim, mas, por isso, não menos relevante, sugere-se considerar o desafio da formulação de alternativas à inevitabilidade do desenvolvimento desigual enquanto limite para a mudança social.

\section{Palavras chave}

Capitalismo; desenvolvimento geográfico desigual; espaço; lei do desenvolvimento desigual e combinado; mundialização.

\begin{abstract}
The aim with this article is to revisit the law of uneven and combined development, highlighting its contribution to the geography of the globalized capitalism. Although the origin of this known law can be found in the work of Marx, it was formulated, in the terms that matter here, by Leon Trotsky. The geographic link is obvious. But it is only since the early 1980s that the Geography (in particular, by the works of David Harvey and Neil Smith) brought the questions on socio-spatial inequality to the debate. To achieve the aim proposed, this text was divided into two sections - plus the introduction and the final considerations: in the first section the uneven development is characterized in order to approximate the question of socio-spatial inequalities to the law of uneven and combined development; in the second section it is examined the specific geographical character of uneven development. In the final considerations the dialogues by some Brazilian intellectuals with the law of uneven and combined development, as well as their (involuntary) contributions to the uneven geographical development approach, are revised. Last but not least, it is suggested to consider the possibility of elaborating alternatives to the inevitability of uneven development as a limit for social change.
\end{abstract}

\section{Key words}

Capitalism; globalisation; law of uneven and combined development; space; uneven geographical development. 


\section{INTRODUÇÃO}

Faz pelo menos um quarto de século que "a globalização se tornou uma palavra-chave para a organização de nossos pensamentos no que respeita ao funcionamento do mundo" (HARVEY, 2004, p. 79). Desde então muito se tem falado e escrito sobre a globalização e sobre como ela afeta a vida de indivíduos, firmas e países. Contudo, todo o debate sobre globalização pode ser decretado quase irrelevante se se ignora o fato crucial de que a burguesia é impelida, pelo imperativo de ampliar os mercados para os valores de troca que produz, a invadir e ocupar cada canto do planeta. O fato, realmente, mais que crucial, portanto, é que a burguesia necessita se estabelecer em todos os espaços. E, em absolutamente todos, ela precisa explorar todas as suas possibilidades. Como resultado desse impulso, desde o surgimento do capitalismo, com intensidade crescente desde a Revolução Industrial, a burguesia vem expandindo a exploração do mercado mundial e conferindo um caráter cosmopolita à produção e ao consumo em todas as economias nacionais (MARX; ENGELS, 1990/1848, p. 465-466).

Se, desde os anos 1970, a internacionalização da economia capitalista atinge um novo patamar, é porque o velho regime de acumulação se tornara demasiadamente restritivo. Portanto, pode-se falar de globalização - ou do que se quiser - se o fato referido for devidamente considerado e se levar na devida conta que um regime de acumulação, com dominância financeira, vai se mundializando (CHESNAIS, 1996).

Com a indústria moderna se configura uma divisão territorial do trabalho específica do capitalismo. A geografia herdada, na forma das regiões econômicas anteriormente existentes, é completamente modificada - cada vez mais por inovações nos meios de comunicação e transportes. As atividades previamente dominantes dão lugar a outras. Algumas desaparecem, outras novas surgem. Espaços economicamente relevantes no passado são tornados irrelevantes no presente. Desertos econômicos são convertidos em espaços industriais pujantes. Todavia, uns e outros "são integrados nas economias nacionais e internacionais, como parte de uma nova configuração espacial” (SMITH, 1988, p. 208).

Essa nova configuração espacial representa um paradoxo: a "conformação" geográfica do capitalismo serve tanto para desenvolver o sistema quanto para questioná-lo e, quiçá, superá-lo. A fim de desenvolver esta hipótese, propõe-se aqui revisitar a lei do desenvolvimento desigual e combinado, destacando a sua especificidade para a geografia no capitalismo mundializado. Para tanto, o artigo foi dividido 
em duas seções principais, além desta introdução e das considerações finais: a primeira seção caracteriza o desenvolvimento desigual na aproximação do tema pela lei do desenvolvimento desigual e combinado; a segunda seção consiste na discussão do caráter especificamente geográfico do desenvolvimento desigual; nas considerações finais resgatam-se os diálogos travados por alguns intelectuais brasileiros com a lei do desenvolvimento desigual e combinado, assim como suas contribuições (involuntárias) para o enfoque do desenvolvimento geográfico desigual. O propósito é o de identificar pistas alternativas à inevitabilidade do desenvolvimento desigual enquanto limite para a mudança.

\section{SOBRE A LEI DO DESENVOLVIMENTO DESIGUAL E COMBINADO}

A noção de desenvolvimento geográfico desigualé recente. Mas, a de desenvolvimento desigual tem origens um pouco mais remotas. Consta que tenha sido Lênin (1982) quem, pela primeira vez, examinou com maior profundidade um processo - o desenvolvimento do capitalismo na Rússia - da perspectiva de sua desigualdade socioeconômica. No entanto, foi depois da Revolução de 1905 que a noção de desenvolvimento desigual, por intermédio de Leon Trotsky, ganhou um significado mais preciso. Aliás, com Trotsky, ela passou a ser desenvolvimento desigual e combinado, uma lei que já não dizia respeito apenas à dimensão econômica, mas remetia a uma questão política imediata ${ }^{1}$.

Convém distinguir a tentativa (que vários geógrafos vêm empreendendo) de construir uma teoria do desenvolvimento geográfico desigual da lei do desenvolvimento desigual e combinado, como formulada por Trotsky². Esta lei integra já uma teoriaa teoria da revolução permanente. A formulação mais completa da referida lei parece encontrar-se no capítulo inicial do primeiro volume da História da Revolução Russa. Aí, com efeito, se lê que

1 "Esse foi o conceito [desenvolvimento desigual e combinado] que Trotsky resgatou e depurou [...] Hoje a lei do desenvolvimento desigual e combinado está claramente associada à tradição trotskista [...] o conceito caiu na obscuridade, mas não antes que seu conteúdo econômico e geográfico estivesse completamente deslocado" (SMITH, 1988, p. 18; ver também p. 150). O conteúdo econômico e geográfico (mas, não o seu deslocamento) será examinado mais à frente; todavia, cabe uma palavrinha sobre a afirmação de que o conceito [de desenvolvimento desigual] tenha caído na obscuridade. Para Ernest Mandel, bem ao contrário, "a idéia de desenvolvimento desigual e combinado do capitalismo mundial é - com a exceção da concepção de Marx sobre a determinação econômica da luta de classes - a tese marxista mais amplamente assimilada desde há meio século, mesmo que raramente seja feita referência ao seu autor" (LÖWY, s.d., p. 79).

2 Como se verá, uma tentativa com a qual, sobretudo, Neil Smith e David Harvey têm estado comprometidos. 
Ivo Marcos Theis

O desenvolvimento de uma nação historicamente atrasada conduz, necessariamente, a uma combinação original das diversas fases do processus histórico. A órbita descrita toma, em seu conjunto, um caráter irregular, complexo, combinado [...] A desigualdade do ritmo, que é a lei mais geral do processus histórico, evidencia-se com maior vigor e complexidade nos destinos dos países atrasados. Sob o chicote das necessidades externas, a vida retardatária vê-se na contingência de avançar aos saltos. Desta lei universal da desigualdade dos ritmos decorre outra lei que, por falta de denominação apropriada, chamaremos de lei do desenvolvimento combinado, que significa aproximação das diversas etapas, combinação das fases diferenciadas, amálgama das formas arcaicas com as mais modernas. Sem esta lei, tomada, bem entendido, em todo o seu conjunto material, é impossível compreender a história da Rússia, como em geral a de todos os países chamados à civilização em segunda, terceira ou décima linha (TROTSKY, 1978, p. 25).

Como Trotsky chegou a essa formulação? Ao que tudo indica, ele teria começado

[...] a prestar séria atenção ao desenvolvimento desigual na situação revolucionária de 1905 na Rússia, quando, como em todas as situações revolucionárias, as leis econômicas da sociedade perdem progressivamente sua validade em favor de uma direta determinação política da história (SMITH, 1988, p. 237 - especificamente, a terceira nota ao capítulo quatro).

Caberia discutir em que medida as leis econômicas da sociedade perdem validade- $\mathrm{O}$ que, porém, não é propósito aqui. Contudo, parece certo que a lei do desenvolvimento desigual e combinado pode ser interpretada como tentativa de conferir maior autonomia à esfera política ${ }^{3}$.

Aliás, a acima referida passagem de Leon Trotsky revela que o caráter desigual e combinado (das relações sociais de produção nas formações sociais periféricas) repousa na articulação entre o capital urbano-industrial com a propriedade rural, entre as classes possuidoras da cidade e do campo. Mas, em países capitalistas periféricos - como era o caso da Rússia no início do século XX o desenvolvimento da economia urbana e da economia rural é marcado por ritmos e velocidades distintos, por contradições, por rupturas abruptas. Logo, mudanças políticas não podem ser deduzidas mecanicamente de um desenvolvimento economicamente pré-determinado. As contradições do desenvolvimento desigual e combinado nas formações sociais periféricas requerem que se considerem suas

3 Embora Michael Löwy (s.d., p. 73-74) afirme que "a teoria do desenvolvimento desigual e combinado de Trotsky [...] é uma tentativa de [...] dar conta da lógica das contradições econômicas e sociais dos países do capitalismo periférico ou dominados pelo imperialismo" [grifo meu]. Note-se que Löwy fala de lógica das contradições econômicas e sociais, subentendendo, mas não explicitando, a presença da dimensão política. No entanto, surpreende mesmo que ele fale em teoria do desenvolvimento desigual e combinado - o que neste contexto é novo. 
especificidades - o que aponta, evidentemente, para a autonomia do nível sóciopolítico (LÖWY, 1981, p. 97-98).

De 1930 - ano em que foi publicada a História da Revolução Russa - em diante, a noção de desenvolvimento desigual parece ter se estabelecido sob a forte influência de Leon Trotsky - portanto, com essa compreensão de um processo que remete a mudanças políticas. Desde os anos 1980, o tema do desenvolvimento desigual e combinado, na sua formulação trotskista, voltou ao debate ${ }^{4}$.

Este é o ponto de partida para a análise do desenvolvimento desigual. Mas, sem que se negue seu significado político, o que se persegue aqui é uma compreensão da espacialidade do desenvolvimento socioeconomicamente desigual - tarefa que se procurará cumprir a seguir.

\section{SOBRE A TEORIA DO DESENVOLVIMENTO GEOGRÁFICO DESIGUAL}

Como já foi dito, a noção de desenvolvimento desigual tem origem em Lênin e, na tradição política de interpretação do desenvolvimento capitalista da Rússia, ela adquiriu maior importância na formulação de Trotsky. A noção de desenvolvimento geográfico desigual, que é a que aqui interessa, é bem mais recente e precisa ser associada aos esforços que, especialmente, geógrafos têm feito no sentido de construir uma teoria do desenvolvimento desigua $\bar{F}$. O que distingue a lei do desenvolvimento desigual e combinado da teoria do desenvolvimento geográfico desigual é: enquanto a preocupação da primeira está em explicar porque uma formação social periférica/ atrasada, cujas forças produtivas não estão desenvolvidas e nem sob o controle de uma burguesia nacional consolidada, pode experimentar uma revolução política; a segunda constitui uma tentativa teórico-metodológica que busca captar a espacialidade do desenvolvimento desigual, portanto, a natureza especificamente geográfica da desigualdade socioeconômica entre regiões e países ${ }^{6}$.

4 Aqui caberia destacar a presença destacada de Michael Löwy. De sua lavra precisam ser consultados, por exemplo, os aqui referidos the politics of combined and uneven development (1981) e a teoria do desenvolvimento desigual e combinado (s.d.).

5 Antes da publicação da obra de Neil Smith, em 1984, já haviam conhecido a luz do mundo duas importantes contribuições oriundas da geografia marxista: as de David Harvey (1982) e M. Dunford e D. Perrons (1983).

6 A insistência para com a espacialidade do desenvolvimento desigual é devida à tendência da teoria social de excluir a espacialidade de toda análise ou de tratá-la como mero container imutável no interior do qual ocorrem processos sociais. O enfoque do desenvolvimento geográfico desigual propicia uma concepção de espaço como relativo e relacional (HARVEY, 2006). 
Ivo Marcos Theis

Talvez deva ser dito mais: não se trata da desigualdade socioeconômica entre espaços geográficos em geral, mas da produzida pelo capitalismo. Em outros termos: é a geografia do desenvolvimento desigual especificamente capitalista que importa aqui'. E esta principia pela diferenciação do espaço geográfico que resulta dos processos sociais cotidianos.

Com efeito, tudo o que se passa no local de trabalho e no processo de produção e consumo está, de algum modo, contido no interior do processo mais amplo de acumulação e circulação de capital. Quase tudo o que se come e bebe, veste e usa, ouve e vê, vem em forma de mercadorias e está perpassado por divisões do trabalho, assim como por discursos e ideologias que difundem os preceitos do capitalismo. Entretanto, isso tudo (mercadorias e processos) não está fora do espaço: a competição territorial por trás das relações do cotidiano tem uma importância incomum no processo de acumulação de capital e no desenvolvimento geográfico desigual (HARVEY, 2006, p. 82-85).

Se a geografia do desenvolvimento desigual principia pela diferenciação do espaço geográfico, então o seu início está definido pela divisão territorial do trabalho. À localização de certos setores da economia e certos gêneros da indústria, isto é, à concentração de unidades produtivas destes setores e gêneros em determinados lugares/regiões é que se chama de divisão territorial do trabalho. Ela abarca uma escala maior que a urbana, que conforma um único mercado de trabalho geográfico; mas, uma escala menor que a internacional, onde a mobilidade do trabalho entre diferentes países é absolutamente limitada. De maneira que se pode identificar uma divisão interregional de trabalho, ou seja, "a cristalização de regiões geográficas distintas na escala nacional”, de forma análoga a uma divisão internacional do trabalho, ou seja, uma "divisão global entre o mundo desenvolvido e o mundo subdesenvolvido" (SMITH, 1988, p. 159, 207-208).

E como se dão tais diferenciações geográficas?

[...] o avanço da divisão específica de trabalho pode ter um efeito mais abrangente. A introdução de novas tecnologias pode bem ser responsável [...] pela diferenciação do espaço nas escalas interurbanas, regionais ou mesmo internacional (SMITH, 1988, p. 163-164).

7 Embora Ernest Mandel tivesse insistido na suposta validade universal da lei do desenvolvimento desigual e combinado. É evidente: não se pode negar que o desenvolvimento pré-capitalista tenha sido desigual. Todavia, as razões para a desigualdade pré-capitalista foram bastante distintas das que caracterizam a desigualdade sob o capitalismo (SMITH, 1988, p. 151). Notese que a insistência na validade universal da desigualdade sugere que traços e valores específicos ao capitalismo estivessem presentes em modos de produção anteriores. No entanto, essa intuição requereria não uma formulação da história do capitalismo, mas de toda a civilização (WOOD, 2003). 
Aqui aparece, pois, a tecnologia como elemento capaz de promover ou ampliar a diferenciação do espaço. Embora não se possa tratar do tema com a profundidade desejada, cabe notar que a tecnologia entra no processo de acumulação de capital pela porta da frente, por assim dizer (ROMERO, 2005). Os excedentes produzidos pelo processo de produção são, hipoteticamente, investidos na aquisição de novas máquinas, expandindo o potencial de acumulação. Novos e maiores excedentes são gerados - e, novamente, invertidos na expansão da capacidade produtiva. Assim, a tecnologia está presente tanto no capital fixo, a partir do qual se geram os excedentes iniciais, quanto nas novas máquinas, que ampliam, continuamente, a capacidade produtiva. De forma que "a tecnologia é tanto o veículo para a expansão do capital quanto o fator impulsionador de tal desenvolvimento. A competição é o fluxo social que generaliza a necessidade de inovação por toda a economia" (SMITH, 1988, p. 171).

Do lado de fora da unidade produtiva, a tecnologia também opera seus milagres - com a involuntária geração de impactos sobre a geografia da produção. Se bem que o fabricante de meios de comunicação e transportes opere capitalisticamente e, com sua produção, tenda a gerar excedentes na média da economia nacional (no interior da qual produz suas mercadorias), as mercadorias mesmas deste fabricante, ao se generalizarem pela economia não apenas difundem o uso das novas tecnologias destes gêneros (meios de comunicação e transportes) pela natureza dessas mercadorias, elas alteram a mobilidade do capital (e, hipoteticamente, do trabalho). Portanto, modificam os espaços, diferenciandoos, redesenhando a divisão territorial do trabalho ${ }^{8}$.

A essas modificações que ocorrem nos espaços em decorrência da introdução de novas tecnologias nos meios de comunicação e transportes Marx chamou de $a$ aniquilação do espaço pelo tempo ${ }^{9}$. O raciocínio é simples: distâncias que precisam ser percorridas (por pessoas, sim, mas, aqui, se trata de mercadorias e informações, um tipo específico de mercadoria) implicam em custos de movimentação. Custos são reduzidos nestes casos se distâncias puderem ser reduzidas ou vencidas em tempo menor. Meios de comunicação e transportes são as mercadorias capazes

8 Ver Smith (1988, p. 172). A título de exemplo, novas tecnologias em meios de comunicação e transportes podem levar a que certas produções em certos espaços floresçam, enquanto outras produções localizadas em outros espaços não poderão se beneficiar delas - o que gerará novas desigualdades geográficas (HARVEY, 2006).

9 Em alemão: “die Vernichtung des Raums durch die Zeit”. Trata-se de uma das passagens das mais geográficas que se encontram nos escritos de Karl Marx (1983 [1857/1858], p. 430-431). 
Ivo Marcos Theis

de atender a essas exigências do capital - em todas as escalas. Por sua natureza, inovações contínuas nessas mercadorias contribuem para que o mundo se torne cada vez menor - e cada vez mais desigual ${ }^{10}$.

Com o tempo, a competição intercapitalista promove relocalizações da atividade econômica em direção a regiões mais vantajosas, isto é, mais lucrativas, para formas específicas de produção de mercadorias. De fato, a competição intercapitalista reconfigura, permanentemente, o território. Espaços urbanos são privilegiados por concentrarem funções de comando e controle, pesquisa e desenvolvimento, marketing e finanças, assim se tornando particularmente atrativos para certos capitais e certas formas de produção - o que pode levar a economias de aglomeração. Se a competição entre regiões, e mesmo entre outras unidades territoriais, governa a dinâmica capitalista, então a emergência de regiões bemsucedidas e centros de acumulação de capital altamente competitivos afeta a situação global. Se uma dada região se torna a mais dinâmica e bem-sucedida na produção de certo bem, ela passa a ser referência para o mundo em termos de custos, condições de trabalho, padrão tecnológico, organização sindical etc. ${ }^{11}$

De qualquer maneira, desses processos de centralização e dispersão resulta uma paisagem geográfica em constante mudança. Regiões bem-sucedidas são espaços nos quais a economia tende a crescer e a sociedade a se tornar mais rica; regiöes perdedoras, em contrapartida, constituem espaços nos quais o processo de acumulação parece estar travado e sua sociedade, em consequência, parece empobrecer além da pobreza herdada. De fato, regiões bem-sucedidas e regiões perdedoras conformam a paisagem do capitalismo mundializado, expressão concreta do desenvolvimento geográfico desigual. O capital ignora os espaços em que as perspectivas de lucro são baixas e, por entre as diversas escalas, se move em direção aos espaços em que as perspectivas de lucro são as mais altas. Daí que regiões perdedoras de ontem podem ser as que propiciem melhores condições de valorização para o capital amanhã. Por isso, num momento seguinte, uns espaços experimentam taxas elevadas, outras taxas reduzidas de acumulação. Entretanto, no contexto do admirável mundo novo do capitalismo mundializado, e contrariando os

10 Ver, a propósito, entre outros, Gregory Albo (2004), David Harvey (2006), Doreen Massey (1991) e Neil Smith (2000).

11 Ver Harvey (2006). A mesma ideia já estava presente no jovem Lipietz (1988, p. 96), quando afirmou que "o desenvolvimento desigual das regiões mundiais (definidas como zonas homogêneas de articulação dos modos de produção e de dominação real do capital) permite ao capitalismo monopolista redefinir a alocação do capital e o processo de trabalho internacional, apreendendo essas mesmas diferenças como funcionais à divisão do trabalho no interior de um processo de valorização do capital único". 
cânones do neoliberalismo, todos ficam à espera de que uma mão visivel opere algum milagre - por exemplo, force a realização de investimentos públicos (HARVEY, 2006; SMITH, 1988).

A co-existência, simultânea e dinâmica, de espaços mais desenvolvidos e menos desenvolvidos é o resultado do desenvolvimento geográfico desigual. Mas, também, é condição para o processo de continuada valorização do capital. Ora, aqui se pode reconhecer o duplo caráter do processo:

O desenvolvimento desigual é tanto o produto quanto a premissa geográfica do desenvolvimento capitalista. Como produto, o padrão é altamente visível na paisagem do capitalismo, tal como a diferença entre espaços desenvolvidos e subdesenvolvidos em diferentes escalas: o mundo desenvolvido e o subdesenvolvido, as regiões desenvolvidas e as regiões em declínio, os subúrbios e o centro da cidade. Como premissa da expansão capitalista, o desenvolvimento desigual [...] é a desigualdade social estampada na paisagem geográfica e é simultaneamente a exploração daquela desigualdade geográfica para certos fins sociais determinados (SMITH, 1988, p. 221).

É certo, pois, que o desenvolvimento geográfico desigual se manifesta como resultado e como condição. Assim, para captá-lo mais completamente, é preciso que se retenha dois elementos principais: "a mudança das escalas e a produção de diferenças geográficas. Temos, por conseguinte, de pensar em diferenciações, interações e relações tanto inter-escalares como intra-escalares" (HARVEY, 2004, p. 112).

\section{CONSIDERAÇÕES FINAIS}

No âmbito deste debate, alguns intelectuais partiram, explícita ou implicitamente, do desenvolvimento desigual e combinado - e, involuntariamente, do desenvolvimento geográfico desigual - para analisar o caso brasileiro.

Um dele foi Milton Santos. Ele aceitou o desafio de tratar a urbanização desigual, levando em conta as categorias de tempo e espaço. Lembrando que a urbanização moderna acompanhou a Revolução Industrial, ele mostrou, acertadamente, que a tendência era fazer a correlação com os países subdesenvolvidos. Traçando um paralelo entre industrialização e urbanização, ele demonstrou o equívoco da tese de que a urbanização dos países subdesenvolvidos seria uma repetição da urbanização dos países desenvolvidos (SANTOS, 1980).

A seu modo, essa tese também estava presente nas concepções etapista e dualista da Comissão Econômica para a América Latina e o Caribe (CEPAL), 
Ivo Marcos Theis

do Instituto Superior de Estudos Brasileiros (ISEB) e do Partido Comunista Brasileiro (PCB) - neste caso, essa noção é facilmente identificada com a influência do stalinismo. Comum a essas concepções era a natureza da oposição entre países desenvolvidos e países subdesenvolvidos. Logo, para superar o subdesenvolvimento, considerava-se a possibilidade de uma aliança do proletariado com setores da burguesia, visando uma revolução nacional e anti-imperialista. Os acontecimentos históricos pré-1964 demonstraram que essas concepções eram problemáticas. Acertadamente, a base teórica do pensamento etapista passou a ser questionada, entre outros, por Caio Prado Jr., Florestan Fernandes e Francisco de Oliveira (DEMIER, 2007).

Recorde-se que, ainda no início dos anos 1980, Celso Furtado percebera as possibilidades e as limitações que se apresentavam para as formações periféricas, dispensando um vaticínio que a história provaria certeiro:

Temos que interrogar-nos se os povos da periferia vão desempenhar um papel central na construção da própria história, ou se permanecerão como espectadores enquanto o processo de transnacionalização define o lugar que a cada um cabe ocupar na imensa engrenagem que promete ser a economia globalizada do futuro (FURTADO, 1982, p. 132).

Francisco de Oliveira, ao analisar o caso brasileiro, e em consonância com Furtado, mas fazendo referência explícita à fonte teórica da análise das desigualdades, perceberia que:

A evidente desigualdade de que se reveste que [para usar a expressão famosa de Trotsky, é não somente desigual, mas combinada] é produto antes de uma base capitalística de acumulação razoavelmente pobre para sustentar a expansão industrial e a conversão da economia pós-anos 30, que da existência de setores "atrasado" e "moderno" (OLIVEIRA, 1987, p. 36).

Para ele, a particularidade do desenvolvimento brasileiro consistiria em introduzir características modernas no arcaico - e introduzir características arcaicas no moderno. Além dessa particularidade, outro ponto que, posteriormente, seria trazido à superfície por Francisco de Oliveira é a desigualdade política. Para ele:

[...] os que fazem a política distinguem-se por pautar os movimentos do outro, do adversário, por impor-lhe minimamente uma agenda de questões sobre as quais e em torno das quais se desenrola o conflito. Impor a agenda não significa necessariamente ter êxito, ganhar a disputa; antes, significa criar um campo específico dentro do qual o adversário é obrigado a se mover. É evidente que o adversário, em seus movimentos, tenta, por sua vez, desvencilhar-se da pauta e sair fora da agenda que lhe é oferecida/imposta. É nesse intercâmbio, desigual, que se estrutura o próprio conflito ou jogo da política (OLIVEIRA, 2007, p. 15). 
Na política existe a capacidade de se construir hegemonia. Ela faz com que todos joguem com linguagens, situações, instituições e culturas inventadas - que se tornam cultura dominante. "A sociedade civil fica restrita aos arranjos locais e localizados, enquanto as operações da política se tornam reserva de caça das grandes empresas e do mercado" (OLIVEIRA, 2007, p. 42).

Talvez se deva concordar com Francisco de Oliveira (2007, p. 42), também, quando insiste que vivemos num período de indeterminação. Aí existem experiências inventivas. Todavia, estas não se situam no campo dos conflitos. A política é apropriada pelos partidos e pelas empresas e o espaço do conflito é esvaziado. David Harvey (2004, p. 98), por sua vez, mostra que "condições desiguais oferecem abundantes oportunidades de organização e ação política". Assim, tanto a lei do desenvolvimento desigual e combinado quanto o enfoque do desenvolvimento geográfico desigual oferecem valiosas pistas sobre o paradoxo da contemporânea geografia do capitalismo mundializado, rompendo com a inevitabilidade do desenvolvimento desigual enquanto limite para a mudança.

\section{REFERÊNCIAS}

ALBO, Gregory. A velha e a nova economia do capitalismo. Socialist Register 2004, p. 127-158, 2004.

CHESNAIS, François. A mundialização do capital. São Paulo: Xamã, 1996.

DEMIER, Felipe. A lei do desenvolvimento desigual e combinado de Leon Trotsky e a intelectualidade brasileira: breves comentários sobre uma relação pouco conhecida. Revista Outubro, São Paulo, n. 16, p. ...-..., 2007.

DUNFORD, M.; PERRONS, D. The arena of capital. Nova Iorque: St. Martin's Press, 1983.

FURTADO, Celso. A nova dependência: dívida externa e monetarismo. Rio de Janeiro: Paz e Terra, 1982.

HARVEY, David. Spaces of global capitalism: towards a theory of uneven geographical development. London; New York: Verso, 2006.

Espaços de esperança. Trad.: A. U. Sobral; M. S. Gonçalves. São Paulo: Loyola, 2004.

The limits to capital. Oxford: Basil Blackwell, 1982.

LÊNIN, Vladimir Ilitch. O desenvolvimento do capitalismo na Rússia: o processo de formação do mercado interno para a grande indústria. Trad. Jose Paulo Netto. São Paulo: Abril Cultural, 1982. 
Ivo Marcos Theis

LIPIETZ, Alain. O capital e seu espaço. Trad.: Manoel F. Gonçalves Seabra. São Paulo: Nobel, 1988.

LÖWY, Michael. A teoria do desenvolvimento desigual e combinado. Revista Outubro, São Paulo, p. 73-80, s.d.

The politics of combined and uneven development: the theory of permanent revolution. London: Verso, p. 97, 1981.

MARX, Karl. "Einleitung [zu den "Grundrissen der Kritik der politischen Ökonomie]”. In: Ökonomische Manuskripte 1857/1858 (= MEW, Band 42). Berlin: Dietz Verlag, 1983. p. 430-431.

MARX, Karl; ENGELS, Friedrich. Manifest der kommunistischen Partei (= MEW, Band 4). Berlin: Dietz Verlag, 1990 [1848].

MASSEY, Doreen. A global sense of place. Marxism Today, p. 24-29, jun. 1991.

OLIVEIRA, Francisco de. Política numa era de indeterminação: opacidade e reencantamento. In: OLIVEIRA, Francisco de; RIZEK, Cibele Saliba (org.) A era da indeterminação. São Paulo: Boitempo, 2007. p. 15-45.

A economia brasileira: crítica a razão dualista. 5. ed. Petrópolis: Vozes, 1987.

ROMERO, Daniel. Marx e a técnica. São Paulo: Expressão Popular, 2005.

SANTOS, Milton. A urbanização desigual: a especificidade do fenômeno urbano em países subdesenvolvidos. Petrópolis: Vozes, 1980.

SMITH, Neil. Contornos de uma política espacializada: veículos dos sem-teto e produção de escala geográfica. In: ARANTES, Antonio A. P. (org.) O espaço da diferença. Campinas: Papirus, 2000. p. 132-159.

. Desenvolvimento desigual: natureza, capital e a produção de espaço. Trad.: Eduardo de Almeida Navarro. Rio de Janeiro: Bertrand Brasil, 1988.

TROTSKY, Leon. A história da revolução russa. Trad.: E. Huggins. 3. ed. Rio de Janeiro: Paz e Terra, 1978. (Primeiro volume)

WOOD, Ellen M. Democracia contra capitalismo: a renovação do materialismo histórico. Trad.: Paulo Cezar Castanheira. São Paulo: Boitempo, 2003.

Texto submetido à Revista em maio e aceito para publicação em novembro de 2009 